\title{
The Theoretical Description for the Electrochemical Determination of Anti-COVID-19 Drug Umifenovir, Assisted by a Poly(squaraine dye-co-naphthoquinones) Composite with $\mathrm{CoO}(\mathrm{OH})$, Paired with $\mathrm{CoO}_{2}$
}

\author{
Volodymyr V. Tkach ${ }^{1,2}$,*(D), Marta V. Kushnir ${ }^{1}$ (D) , Sílvio C. de Oliveira ${ }^{2}$ (D), Yana G. Ivanushko ${ }^{3}$ (D), Alla

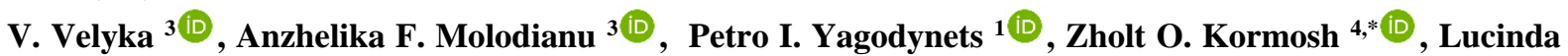 \\ Vaz dos Reis ${ }^{5(D)}$, Olga V. Luganska ${ }^{6}$ (D), Karina V. Palamarek ${ }^{7}$, , Yulia L. Bredikhina ${ }^{8,9}$ (D), \\ Adriano O. da Silva 10 (D)
}

1 Chernivtsi National University, 58000, Kotsyubyns'ky Str. 2, Chernivtsi, Ukraine; nightwatcher2401@ gmail.com (V.V.T.), ved1988mid@ rambler.ru (P.I.Y.), marta.v.kushnir@gmail.com (M.V.K.);

2 Universidade Federal de Mato Grosso do Sul, Av. Sen. Felinto. Müller, 1555, C/P. 549, 79074-460, Campo Grande, MS, Brazil; scolive@gmail.com (S.C.O.);

3 Bukovinian State Medical University, 58001, Teatralna Sq., 9, Chernivtsi Ukraine; yana_iv@ukr.net (Y.G.I.), molodianu.anzhelika@bsmu.edu.ua (A.F.M.), alla.velyka@gmail.com (A.V.V.);

4 Eastern European National University, 43000, Voli Ave., 13, Lutsk, Ukraine; zholt-1971@ukr.net (Z.O.K.), kormosh@eenu.edu.ua (Z.O.K.);

5 Universidade de Trás-os-Montes e Alto Douro, Quinta de Prados, 5001-801, Folhadela, Vila Real, Portugal; lucinda.reis@utad.pt (L.V.R.);

6 Zaporizhzhia National University, 69600, Zhukovsky Str. 66, Zaporizhzhia, Ukraine; 130805olga@gmail.com (O.V.L.)

7 Chernivtsi Institute of Trade and Economics of KNTEU, 58000, Central Sq, 9, Chernivtsi, Ukraine; karinkap55@gmail.com (K.V.P.);

8 Melitopol State Pedagogical University, 72300, Melitopol, Hetmanska Str., 20, Ukraine; cvetochek.jul@ ukr.net (Y.L.B.);

9 Khortytska Natsionalna Navchalno-Reabilitatsiyna Akademiya, 69000, Naukove Mistechko, 59, Khortytsia Island, Zaporizhzhia, Ukraine

10 Universidade Federal do Oeste do Pará, Campus Juriti, Rua V. de Souza Andrade, s/n, 68170-000, Juriti, PA,Brazil; ollympio@gmail.com (A.O.S.);

* Correspondence: nightwatcher2401@gmail.com (V.V.T.); ved1988mid@ rambler.ru (P.I.Y.);

Scopus Author ID 55758299100

Received: 10.08.2020; Revised: 27.09.2020; Accepted: 30.09.2020; Published: 4.10.2020

\begin{abstract}
For the first time, the system with anti-COVID19 drug umivenofir electrochemical determination, assisted by a Squaraine Dye - $\mathrm{CoO}(\mathrm{OH}) / \mathrm{CoO}_{2}$ composite, has been described theoretically. The mechanism contains hydrolysis, chemical, and electrochemical oxidation stages. The correspondent mathematical model has been developed and analyzed using linear stability theory and bifurcation analysis. Despite the branched character of the mechanism, the composite of Squaraine Dye with $\mathrm{CoO}(\mathrm{OH}) / \mathrm{CoO}_{2}$ may be an efficient electrode modifier for the umivenofir determination. However, the oscillatory behavior may be possible, but only because of double electric layer influences on the electrochemical stage.
\end{abstract}

Keywords: COVID-19; umifenovir; electrochemical sensors; squaraine dye; cobalt(III)oxyhydroxide; stable steady-state.

(C) 2020 by the authors. This article is an open-access article distributed under the terms and conditions of the Creative Commons Attribution (CC BY) license (https://creativecommons.org/licenses/by/4.0/). 


\section{Introduction}

Umifenovir [1 - 4] (Fig. 1), sold under the brand name Arbidol is an antiviral drug for treating different types of influenza. It is used mostly in Russia and China. Recently, its efficacy against COVID-19 (sole and alongside darunavir) has been claimed by the study conducted in the mentioned countries [5-11]. Its mechanism of action consists of preventing the contact between the virus and host cells, inhibiting the viral envelope from contacting the cell membrane of the target cell. Therefore, the infection of the target cell is impeded. Besides influenza, it has already been used to treat Zaire ebolavirus [12], Kaposi's sarcoma-associated herpesvirus [13].

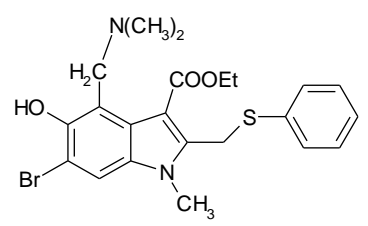

Figure 1. Umifenovir.

Nevertheless, the drug is not widely used in Western democratic countries. Most of the articles describing its investigation were published in Russian, making it difficult to analyze their quality by the WHO. US, the Food and Drug Administration. Moreover, even within Russia, its efficacy of Umifenovir has been questioned [14 - 15]. Also, the side effects are not known well. Therefore, the development of a method capable of detecting rapidly and efficiently the concentration of Umifenovir is an actual task [16 - 18].

Considering the composition of Umifenovir (as an indolic derivative, substituted by electroactive groups), it is possible to conclude that it has to be electrochemically active. Similar compounds [19-28] (both drugs and pesticides) have already been used as analytes in electrochemical sensors, involving the chemically modified electrodes with hybrid materials. In these materials, the redox-active metal oxides are stabilized by conjugated oligomers (squaraine dyes) and polymers, acting as stabilizers and mediators [29-35].

Nevertheless, the organic electrooxidation processes (including the electropolymerization) tend to be accompanied by electrochemical instabilities, similar to those observed in BZ and BR reactions. These instabilities include the oscillatory changes in electrochemical potential and monotonic instabilities [36-38] and influence the analytical signal interpretation and reproducibility.

Therefore, in this system, we investigate the system with the electrochemical determination of Umifenovir, assisted by the composite of poly (squaraine dye-co-naphthoquinones) composite with cobalt (III) oxyhydroxide, paired with the cobalt dioxide. In order to realize this task, we realize the specific goals like the suggestion of the most probable mechanism for the reaction sequence, leading to the electroanalytical signal realization, development and analysis of the mathematical model, correspondent to the mechanism, derivation of the steady-state stability conditions and oscillatory and monotonic instability requirements and compare the behavior of this system with that of the similar ones [39-42].

\section{Materials and Methods}

\subsection{System and its modeling.}

The process of the electrochemical determination of the Umifenovir, assisted by the poly(squaraine dye-co-naphthoquinones)- $\mathrm{CoO}(\mathrm{OH}) / \mathrm{CoO}_{2}$ composite is similar to that 
observed for the pyriproxyfen pesticide [39], but somehow more branched. It is represented in Fig. 2:

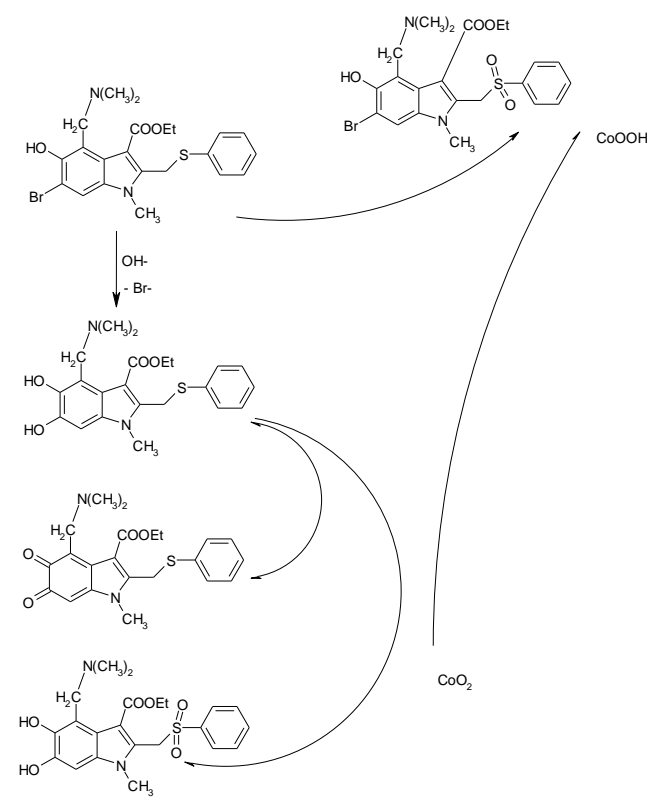

Figure 2. Umifenovir electrochemical determination scheme.

The Cobalt dioxide is regenerated on the electrochemical stage:

$$
\mathrm{CoO}(\mathrm{OH})+\mathrm{OH}^{-}-\mathrm{e}^{-} \rightarrow \mathrm{CoO}_{2}+\mathrm{H}_{2} \mathrm{O}
$$

As Umifenovir is a ternary amine, it has its proper basicity, promoting hydrolysis or $\mathrm{CoO}_{2}$ regeneration reactions.

So, in order to describe the behavior of the electroanalytical system with Umifenovir electrochemical determination, we introduce three variables:

$\mathrm{u}$ - Umifenovir concentration in the pre-surface layer;

$\mathrm{u}^{*}$ - Umifenovir hydrolysis product concentration in the pre-surface layer;

c - cobalt (III) oxyhydroxide matrix coverage degree.

To simplify the modeling, we suppose that the reactor is intensively stirred to neglect the convection flow. Also, we assume that the background electrolyte is in excess of neglecting the migration flow. The diffusion layer is supposed to be of a constant thickness, equal to $\delta$. The concentration profile in it is supposed to be linear. Also, we assume that the oxidation products do not interfere in the reaction.

Therefore, the system's behavior will be described by balance equation-set (2):

$$
\left\{\begin{array}{c}
\frac{d u}{d t}=\frac{2}{\delta}\left(\frac{\Delta}{\delta}\left(u_{0}-u\right)-r_{h}-r_{21}\right) \\
\frac{d u *}{d t}=\frac{2}{\delta}\left(r_{h}-r_{22}-r_{23}\right) \\
\frac{d c}{d t}=\frac{1}{C}\left(r_{21}+r_{22}+r_{23}-r_{1}\right)
\end{array}\right.
$$

Herein, $\Delta$ is the diffusion coefficient, $\mathrm{u}_{0}$ is the bulk drug concentration, $\mathrm{C}$ is the cobalt oxyhydroxide maximal surface concentration, and the parameters $r$ stand for the correspondent reaction rates, calculated as:

$$
\begin{gathered}
r_{21}=k_{21} u(1-c)^{4} \\
r_{h}=k_{h} u \\
r_{22}=k_{22} u *(1-c)^{2} \\
r_{23}=k_{23} u *(1-c)^{4}
\end{gathered}
$$




$$
r_{1}=k_{1} c \exp \left(\frac{F \varphi_{0}}{R T}\right)
$$

In which $\mathrm{k}$ are respective reaction rate constants, $\mathrm{F}$ is the Faraday number, $\mathrm{R}$ is the universal gas constant, and $\mathrm{T}$ is the absolute temperature.

Contrarily to the system with pyriproxyfen electrochemical determination [39], the system will be somehow more dynamic. Nevertheless, the model's analysis shows that the electroanalytical system has to be efficient, as shown below.

\section{Results and Discussion}

In order to describe the behavior of the system with Umifenovir electrochemical determination, assisted by Poly(Squaraine Dye-co-Naphthoquinone)-CoO(OH) composite, we analyze the equation-set (2) using linear stability theory. The steady-state Jacobian matrix members may be described as:

$\left(\begin{array}{lll}a_{11} & a_{12} & a_{13} \\ a_{21} & a_{22} & a_{23} \\ a_{31} & a_{32} & a_{33}\end{array}\right)$

where:

$$
\begin{aligned}
& a_{11}=\frac{2}{\delta}\left(-\frac{\Delta}{\delta}-k_{h}-k_{21}(1-c)^{4}\right) \\
& a_{12}=0 \\
& a_{13}=\frac{2}{\delta}\left(4 k_{21}(1-c)^{3}\right) \\
& a_{21}=0 \\
& a_{22}=\frac{2}{\delta}\left(-k_{22}(1-c)^{2}-k_{23}(1-c)^{4}\right) \\
& a_{23}=\frac{2}{\delta}\left(2 k_{22} u *(1-c)+4 k_{23} u *(1-c)^{3}\right) \\
& a_{31}=\frac{1}{C}\left(4 k_{21}(1-c)^{3}\right) \\
& a_{32}=\frac{1}{C}\left(k_{22}(1-c)^{2}+k_{23}(1-c)^{4}\right) \\
& a_{33}=\frac{1}{C}\left(-4 k_{21}(1-c)^{3}-2 k_{22} u *(1-c)-4 k_{23} u *(1-c)^{3}-k_{1} \exp \left(\frac{F \varphi_{0}}{R T}\right)+\right. \\
& \left.j k_{1} c \exp \left(\frac{F \varphi_{0}}{R T}\right)\right) \quad(17)
\end{aligned}
$$

As in similar systems [39-42], the oscillatory behavior is possible in this system. Nevertheless, as in a bit more simple system with pyriproxyfen electrochemical determination [39], the unique factor responsible for oscillatory behavior is the electrochemical stage's influence on a double electric layer capacitance and conductivity. It is described by the positivity of the element $j k_{2} s \exp \left(\frac{F \varphi_{0}}{R T}\right)>0$ if $\mathrm{j}>0$. The oscillations are expected to be frequent and of small amplitude and are expected to be observed beyond the detection limit.

In order to investigate the steady-state stability, we apply the Routh-Hurwitz stability criterion to the equation-set (2). Avoiding the cumbersome expressions, we introduce new variables, rewriting the determinant as:

$$
\frac{4}{\delta^{2} C}\left|\begin{array}{ccc}
-\kappa-\Xi & 0 & P \\
0 & -\Omega-\Sigma & T+\Phi \\
\Xi & \Omega+\Sigma & -P-T-\Phi-\Lambda
\end{array}\right|
$$

Opening the brackets and applying the condition of Det $\mathrm{J}<0$, salient from the criterion, we obtain the steady-state stability requisite, exposed as:

$$
-\kappa(\Omega P+\Omega \Lambda+\Sigma P+\Sigma \Lambda)-\Xi \Lambda(\Omega+\Sigma)<0
$$


Describing an efficient, although a bit more dynamic, diffusion-controlled electroanalytical system, analogous to [39]. The requisite (19) is warranted to be satisfied within the unique condition of the positivity of the electrochemical parameter $\Lambda$ (as the rest of the variables are always positive).

Considering that no side reaction, capable of compromising the analyte and(or) modifier stability is present in this case, it is possible to conclude that the steady-state stability will be electroanalytical efficient. It corresponds to the linear dependence between the current and Umifenovir concentrations, and it is satisfied for the relatively vast parameter topological region. Therefore, the composite of the copolymer of squaraine dye with naphthoquinones with $\mathrm{CoO}(\mathrm{OH})$ may be an efficient electrode modifier for the electrochemical determination of Umivenofir.

The detection limit is correspondent to the margin between the stable steady-states and unstable states. Its condition is correspondent to the nullity of the determinant and may be exposed as:

$$
-\kappa(\Omega P+\Omega \Lambda+\Sigma P+\Sigma \Lambda)-\Xi \Lambda(\Omega+\Sigma)=0
$$

The model described here is valid for neutral or mildly basic solutions. The ester group also tends to hydrolyze in more fundamental solutions, yielding a more ionic compound, the salt. This will affect the DEL ionic force and may cause the oscillatory behavior, similar to those observed in [36] and foreseen in [40 - 42].

\section{Conclusions}

From the analysis of the system with the Umivenofir electrochemical determination as an anodic process, assisted by $\mathrm{CoO}(\mathrm{OH})$-Poly (Squaraine Dye- Co-Naphthoquinone) composite, it is possible to conclude that; The system's behavior is more dynamic, while compared to the simplest analogous system, due to the direct analyte interaction with the modifier, parallel to the indirect; The electroanalytical process tends to be diffusion controlled with the easy realization of linear dependence between the concentration and the current; The oscillatory behavior tends to have less probability of being realized than similar systems, due to the impossibility of DEL influence of the electrochemical stage.

\section{Funding}

This research received no external funding.

\section{Acknowledgments}

This research has no acknowledgment.

\section{Conflicts of Interest}

The authors declare no conflict of interest.

\section{References}

1. Odnovorov, A.V.; Grebennikova, T.V.; Pleteneva, T.V. Specific Influenza Therapy: Current State and Prospects (Review).Drug Dev. Reg.2020, 9, 83-91, in Russian,https://doi.org/10.33380/2305-2066-2020-91-83-91.

2. Proskurnina, E.V.; Izmailov, D.Y.; Sozarukova, M.M.; Zhuravleva, T.A.; Leneva, I.A.; Poromov, A.A. Antioxidant Potential of Antiviral Drug Umifenovir.Molecules 2020, 25, https://doi.org/10.3390/molecules25071577. 
3. Boriskin, Y.S.; Pecheur, E.L.; Polyak, S.J. Arbidol: A Broad Spectrum Antiviral, that Inhibits Acute and Chronic HCV Infection.Virol. J.2006, 56,https://doi.org/10.1186/1743-422x-3-56.

4. Herod, M.R.; Adeyemi, O.O.; Ward, J.; Bentley, K.; Harris, M.; Stonehouse, N.J.; Polyak, S.J. The broadspectrum antiviral drug arbidol inhibits foot-and-mouth disease virus genome replication. 2019, 100, 12931302,https://doi.org/10.1099/jgv.0.001283.

5. Huang, D.; Yu, H.; Wang, T.; Yang, H.; Yao, R.; Liang, Z. Efficacy and safety of umifenovir for coronavirus disease 2019 (COVID-19): A systematic review and meta-analysis. Journal of Medical Virology 2020, https://doi.org/10.1002/jmv.26256.

6. $\quad$ Liu, W.; Zhou, P.; Chen, K.; Ye, Z.; Liu, F.; Li, X.; He, N.; Wu, Z.; Zhang, Q.; Gong, X.; Tang, Q.; Du, X.; Ying, Y.; Xu, X.; Zhang, Y.; Liu, J.; Li, Y.; Shen, N.; Couban, R.J.; Ibrahim, Q.I.; Guyatt, G.; Zhai, S.Efficacy and Safety of Antiviral Treatment for COVID-19 from Evidence in Studies of SARS-CoV-2 and Other Acute Viral Infections: A Systematic Review and Meta-Analysis.CMAJ2020, 192, e734e744,https://doi.org/10.1503/cmaj.200647.

7. Doi, K.; Ikeda, M.; Hayase, N.; Moriya, K.; Morimura, N.; Maehara, H.; Tagami, S.; Fukushima, K.; Misawa, N.; Inoue, Y.; Nakamura, H.; Takai, D.; Kurimoto, M.; Tokunaga, K.; Yamamoto, M.; Hirayama, I.; Horie, R.; Endo, Y.; Hiwatashi, K.; Shikama, M.; Jubishi, D.; Kanno, Y.; Okamoto, K.; Harada, S.; Okugawa, S.; Miyazono, K.; Seto, Y.; Inoue, J.-I.; Nafamostat mesylate treatment in combination with favipiravir for patients critically ill with Covid-19: a case series. Critical Care 2020, 24,https://doi.org/10.1186/s13054-020-03078-z.

8. Mehta, N.; Mazer-Amirshahi, M.; Alkindi, N.; Pourmand, A. Pharmacotherapy in COVID-19; A narrative review for emergency providers. The American Journal of Emergency Medicine 2020, 38, 1488-1493, https://doi.org/10.1016/j.ajem.2020.04.035.

9. Popov, D. Treatment of COVID-19 Infection. A Rationale for Current and Future Pharmacological Approach.Pulm. Resp. Med.2020, 9, 38-58.

10. Zhong, Q.; Liu, Y.Y.; Luo, Q.; Zou, Y.F.; Jiang, H.X.; Li, H.; Zhang, J.J.; Li, Z.; Yang, X.; Ma, M.; Tang, L.J.; Chen, Y.Y.; Zheng, F.; Ke, J.J.; Zhang, Z.Z. Spinal anaesthesia for patients with coronavirus disease 2019 and possible transmission rates in anaesthetists: retrospective, single-centre, observational cohort study. British Journal of Anaesthesia 2020, 124, 670-675, https://doi.org/10.1016/j.bja.2020.03.007.

11. Viveiros Rosa, S.G.; Santos, W.C. Chemical Trials on Drug Repositioning for COVID-19 Treatment.Rev. Panam. Salud Publ.2020, 44, 1-7.

12. Wang, X.; Cao, R.; Zhang, H.; Liu, J.; Xu, M.; Hu, H.; Li, Y.; Zhao, L.; Li, W.; Sun, X.; Yang, X.; Shi, Z.; Deng, F.; Hu, Z.; Zhong, W.; Wang, M. The anti-influenza virus drug, arbidol is an efficient inhibitor of SARS-CoV-2 in vitro. Cell Discovery 2020, 6,https://doi.org/10.1038/s41421-020-0169-8.

13. Hulseberg, C.E.; Fénéant, L.; Szymańska-de Wijs, K.M.; Kessler, N.P.; Nelson, E.A.; Shoemaker, C.J.; Schmaljohn, C.S.; Polyak, S.J.; White, J.M. Arbidol and Other Low-Molecular-Weight Drugs That Inhibit Lassa and Ebola Viruses. 2019, 93, e02185-02118,https://doi.org/10.1128/JVI.02185-18.

14. Lian, N.; Xie, H.; Lin, S.; Huang, J.; Zhao, J.; Lin, Q. Umifenovir treatment is not associated with improved outcomes in patients with coronavirus disease 2019: a retrospective study. Clinical Microbiology and Infection 2020, 26, 917-921,https://doi.org/10.1016/j.cmi.2020.04.026.

15. Leneva, I.A; Pshenichnaya, N.Y.; Bulgakova, V.A. Umifenovir and Coronavirus Infections: a Review of Research Results and Application Experience in Clinical Practice.Ther. Arch.2020.

16. Annapurna, M.M.; Sri Valli, D.; Chaitanya, S.M. New Stability Indicating Ultrafast Liquid Chromatographic Method for the Determination of Umifenovir in Tablets.Int. J. Green Pharm.2018,12.

17. Leneva, I.A.; Falynskova, I.N.; Makhmudova, N.R.; Poromov, A.A.; Yatsyshina, S.B.; Maleev, V.V. Umifenovir susceptibility monitoring and characterization of influenza viruses isolated during ARBITR clinical study. Journal of Medical Virology 2019, 91, 588-597,https://doi.org/10.1002/jmv.25358.

18. Annapurna, M.M.; Madhuri, V.L.; Sri Valli, D. New Stability Indicating Liquid Chromatographic Method for the Determination of Eplerenone in the Presence of Internal Standart.As. J. Pharm.2018,12, https://dx.doi.org/10.22377/ajp.v12i01.2060.

19. Long, X. Electrochemical Sensors with Antifouling Properties for Sensitive Detection of Isoproturon Based on Glassy Carbon Electrode Modified with Nafion Membrane. International Journal of Electrochemical Science 2020,15, 4964-4977, https://doi.org/10.20964/2020.06.58.

20. Sant'Anna, M.V.S.; Carvalho, S.W.M.M.; Gevaerd, A.; Silva, J.O.S.; Santos, E.; Carregosa, I.S.C.; Wisniewski, A.; Marcolino-Junior, L.H.; Bergamini, M.F.; Sussuchi, E.M. Electrochemical sensor based on biochar and reduced graphene oxide nanocomposite for carbendazim determination. Talanta 2020, https://doi.org/10.1016/j.talanta.2020.121334.

21. Laghrib, F.; Bakasse, M.; Lahrich, S.; El Mhammedi, M.A. Electrochemical sensors for improved detection of paraquat in food samples: A review. Materials Science and Engineering: C 2020, 107,https://doi.org/10.1016/j.msec.2019.110349.

22. Pérez-Fernández, B.; Costa-García, A.; Muñiz, A.D. Electrochemical (Bio)Sensors for Pesticides Detection Using Screen-Printed Electrodes. Biosensors 2020, 10,https://doi.org/10.3390/bios10040032. 
23. Xiang, H.; Cai, Q.; Li, Y.; Zhang, Z.; Cao, L.; Li, K.; Yang, H. Sensors Applied for the Detection of Pesticides and Heavy Metals in Freshwaters. Journal of Sensors 2020, 2020,https://doi.org/10.1155/2020/8503491.

24. Vinothkumar, V.; Sangili, A.; Chen, S.-M. Voltammetric Determination of Sudan I by Using $\mathrm{Bi}_{2} \mathrm{WO}_{6}$ Nanosheets Modified Glassy Carbon Electrode.Int. J. Electrochem. Sci.2020, 15, 2414-2429, https://doi.org/10.20964/2020.03.08.

25. Heydari, M.; Ghoreishi, S.M.; Khoobi, A. Novel electrochemical procedure for sensitive determination of Sudan II based on nanostructured modified electrode and multivariate optimization. Measurement 2019, 142, 105-112,https://doi.org/j.measurement.2019.04.058

26. Karaboduk, K.; Erdoğan, H. Voltammetric Determination of Sudan I in Food Samples Using Its Cu (II) Compound.Food Techn. Biotechn.2018, 56, 573-580, https://doi.org/10.17113/ftb.56.04.18.5679.

27. Tajik, S.; Aflatoonian, M.R.; Shabanzade, R.; Beitollahi, H.; Alizadeh, R. Amplified electrochemical sensor employing $\mathrm{ZnO}-\mathrm{CuO}$ nanoplates for sensitive analysis of Sudan I. International Journal of Environmental Analytical Chemistry 2020, 100, 109-120,https://doi.org/10.1080/03067319.2019.1631304

28. Shah, A. A Novel Electrochemical Nanosensor for the Simultaneous Sensing of Two Toxic Food Dyes. ACS Omega 2020, 5, 6187-6193,https://doi.org/10.1021/acsomega.0c00354

29. Rezvani, J. Synthesis of $\mathrm{Ag}_{2} \mathrm{O}_{2}$ Semiconductor Micropowder by Plasma Electrolysis Method and Its Optical Characterization.Iran J. Cer Sci.2020, 8, 69-79.

30. Lima, E.; Boto, R.; Ferreira, D.; Fernandes, J.; Almeida, P.; Ferreira, L.; Souto, E.B.; Silva, A.M.; Reis, L. Quinoline and Benzoselenazole-Derived Unsymmetrical Squaraine Cyanine Dyes: Design, Synthesis, Photophysicochemical Features and Light-Triggerable Antiproliferative Effects Against Breast Cancer Cell lines.Materials2020, 13, 2646-2660, https://doi.org/10.3390/ma13112646.

31. Gomes, V.S.D.; Gonçalves, H.M.R.; Boto, R.E.F.; Almeida, P.; Reis, L.V. Barbiturate squaraine dyes as fluorescent probes for serum albumins detection. Journal of Photochemistry and Photobiology A: Chemistry 2020, 400,https://doi.org/10.1016/j.photochem.2020.112710.

32. Butnarasu, C.; Barbero, N.; Barolo, C.; Visentin, S. Squaraine dyes as fluorescent turn-on sensors for the detection of porcine gastric mucin: A spectroscopic and kinetic study. Journal of Photochemistry and Photobiology B: Biology 2020, 205,https://doi.org/10.1016/j.photobiol.2020.111838.

33. Maeda, T.; Liess, A.; Kudzus, A.; Krause, A.-M.; Stolte, M.; Amitani, H.; Yagi, S.; Fujiwara, H.; Würthner, F. Hydrogen bond-rigidified planar squaraine dye and its electronic and organic semiconductor properties. Chemical Communications 2020, 56, 9890-9893,https://doi.org/10.1039/D0CC04306K.

34. Chen, Y.; Wang, S.; Li, Z. A cobalt-pyrrole coordination compound as high performance cathode catalyst for direct borohydride fuel cells. RSC Advances 2020, 10, 29119-29127, https://doi.org/10.1039/D0RA05143H.

35. Aguilera, L.; Aguiar, P.C.M.; Ruiz, Y.L.; Almeida, A.; Moreira, J.A.; Passos, R.R.; Pocrifka, L.A. Electrochemical synthesis of $\gamma-\mathrm{CoOOH}$ films from $\alpha-\mathrm{Co}(\mathrm{OH}) 2$ with a high electrochemical performance for energy storage device applications. Journal of Materials Science: Materials in Electronics 2020, 31, 30843091,https://doi.org/10.1007/s10854-019-02853-1.

36. Das, I.; Goel, N.; Agrawal, N.R.; Gupta, S.K. Growth patterns of dendrimers and electric potential oscillations during electropolymerization of pyrrole using mono-and mixed surfactants. J. Phys. Chem. B 2010, 114, 12888-12896, https://doi.org/10.1021/jp105183q.

37. Das, I.; Goel, N.; Gupta, S.K.; Agrawal, N.R. Electropolymerization of pyrrole: Dendrimers, nano-sized patterns and oscillations in potential in presence of aromatic and aliphatic surfactants. Journal of Electroanalytical Chemistry 2012, 670, 1-10,https://doi.org/10.1016/j.elechem.2012.01.023

38. Tkach, V.; Kushnir, M.; Storoshchuk, N.; de Oliveira, S.; Luganska, O.; Parchenko, V.; Bigdan, A.; Yagodynets', P. The Theoretical Description of Cathodic Pyrrole Electrodeposition, Assisted by a Dichromate of a Novel Triazolic Derivative. Rhazes2018, 2.

39. Tkach, V.; de Oliveira, S.; Ojani, R.; Neves, V.S.; Espínola, M.O.; Yagodynetś, P.I. The Theoretical Evaluation for the Possibility of Electrochemical Pyriproxyfen Detection in Water.Anal. Bioanal. Electrochem.2016, 8, 358-366.

40. Tkach, V.; Kushnir, M.; Ivanushko, Y.; de Oliveira, S.; Reis, L.; Yagodynets', P.; Kormosh, Z.The Theoretical Description for Neotame Electrochemical Determination, Assisted by Vanadium Oxyhydroxide Composite with a Squarainic Dye.Appl. J. Env. Eng. Sci.2020, 6, 109-115.

41. Tkach, V.; Kushnir, M.; Storoshchuk, N.; Ivanushko, Y.; de Oliveira, S.; Yagodynets', P.; Kormosh, Z. The Theoretical Description for the Confection of the Novel Thiourea-Based Active Surface for Cathodic Conducting Polymer Deposition, Appl. J. Env. Eng. Sci.2020, 6, 143-148

42. Tkach, V.; Kushnir, M.; Storoshchuk, N.; Ivanushko, Y.; de Oliveira, S.; Yagodynets', P.; Kormosh, Z. The theoretical description for the confection of the novel thiourea- based active surface for cathodic conducting polymer deposition. Appl. J. Env. Eng. Sci. 2020, 6, 143-148. 